\title{
MYCN Positive
}

National Cancer Institute

\section{Source}

National Cancer Institute. MYCN Positive. NCI Thesaurus. Code C131062.

Indicates that MYCN expression has been detected in a sample. 